\title{
The SLICK hair locus derived from Senepol cattle confers thermotolerance to intensively managed lactating Holstein cows
}

\author{
S. Dikmen, ${ }^{*}$ F. A. Khan, $\dagger^{1}$ H. J. Huson, $\ddagger^{2}$ T. S. Sonstegard, $\ddagger$ J. I. Moss, $†$ G. E. Dahl, $†$ and P. J. Hansen $\dagger^{3}$ \\ *University of Uludag, Faculty of Veterinary Medicine, Department of Animal Science, Bursa 16059, Turkey \\ †University of Florida, Department of Animal Sciences, Gainesville 32611-0910 \\ fUSDA, Agricultural Research Service, Animal Genomics and Improvement Laboratory, Beltsville, MD 20705-2350
}

\section{ABSTRACT}

The SLICK haplotype (http://omia.angis.org.au/ OMIA001372/9913/) in cattle confers animals with a short and sleek hair coat. Originally identified in Senepol cattle, the gene has been introduced into Holsteins. The objectives of the current study were to determine (1) whether lactating Holsteins with the slick hair phenotype have superior ability for thermoregulation compared with wild-type cows or relatives not inheriting the SLICK haplotype, and (2) whether seasonal depression in milk yield would be reduced in SLICK cows. In experiment 1, diurnal variation in vaginal temperature in the summer was monitored for cows housed in a freestall barn with fans and sprinklers. Vaginal temperatures were lower in slick-haired cows than in relatives and wild-type cows. In experiment 2 , acute responses to heat stress were monitored after cows were moved to a dry lot in which the only heat abatement was shade cloth. The increases in rectal temperature and respiration rate caused by heat stress during the day were lower for slick cows than for relatives or wildtype cows. Moreover, sweating rate was higher for slick cows than for cows of the other 2 types. In experiment 3 , effects of season of calving (summer vs. winter) on milk yield and composition were determined. Compared with milk yield of cows calving in winter, milk yield during the first $90 \mathrm{~d}$ in milk was lower for cows calving in the summer. However, this reduction was less pronounced for slick cows than for wild-type cows. In conclusion, Holsteins with slick hair have superior thermoregulatory ability compared with non-slick animals and experience a less drastic depression in milk yield during the summer.

\footnotetext{
Received February 27, 2014.

Accepted May 20, 2014.

${ }^{1}$ Present address: Department of Population Medicine, Ontario Veterinary College, University of Guelph, Guelph, ON, N1G 2W1, Canada.

${ }^{2}$ Present address: Department of Animal Science, Cornell University, Ithaca, NY 14853

${ }^{3}$ Corresponding author: Hansen@animal.ufl.edu
}

Key words: heat stress, SLICK locus, body temperature, milk yield

\section{INTRODUCTION}

A largely unexplored strategy to reduce the severity of heat stress effects on dairy cattle is to select cattle genetically for increased thermotolerance. There is genetic variation for heat tolerance in Holsteins (Dikmen et al., 2012) and specific SNP have been identified that are associated with that genetic variation (Hayes et al., 2009; Dikmen et al., 2013). One genetic strategy is to introgress specific genes that confer thermotolerance from cattle breeds that are genetically more resistant to heat stress into dairy breeds that arose in cool climates. Only one such gene has been identified to date - at the SLICK locus. Originally described in the Senepol breed that arose in the Caribbean island of St. Croix and inherited as a single dominant gene, the SLICK haplotype confers animals with a short and sleek hair coat (Olson et al., 2003). The locus has been mapped to bovine chromosome (Chr) 20 (Mariasegaram et al., 2007; Flori et al., 2012). Cows of the Carora breed and Carora $\times$ Holstein crossbreds possessing a phenotype consistent with inheritance of the SLICK haplotype experience lower body temperatures and increased milk yield compared with animals with the wild-type hair coat (Olson et al., 2003). The SLICK haplotype has also been introduced into Holstein cattle: lactating Holsteins with slick hair have superior thermoregulatory ability compared with wild-type Holsteins (Dikmen et al., 2008). In part, this difference reflects an increased rate of thermal sweating (Dikmen et al., 2008).

Herein we describe the results of studies that confirm the superior thermoregulatory ability of Holsteins with slick hair compared with non-slick animals and show that inheritance of the SLICK haplotype reduces the depression in milk yield during the summer in highproducing Holsteins reared in confinement conditions. Results indicate the utility of introgression of the SLICK haplotype for reducing the effect of heat stress on dairy production. 


\section{MATERIALS AND METHODS}

\section{Animals}

Animal use was approved by the University of Florida Institutional Animal Care and Use Committee (approval no. 2009-03578). Lactating cows of 3 genotypes were used. Slick- and normal-haired relatives (15/16 Holstein or greater) were produced from matings of Holsteins ( $7 / 8$ or greater) possessing the slick hair phenotype originally derived from matings with Senepol cattle. The original matings were made around 1990, and offspring were subsequently mated with either wild-type bulls (registered Holstein) or slick bulls that were at least $75 \%$ Holstein.

Slick animals possessed a short and sleek hair coat that was most obvious because of the very short hair on the face and poll and a small switch on the tail (Figure 1). Animals with these phenotypic characteristics were considered to have inherited the SLICK haplotype. Normal-haired offspring were also produced from slick-haired Holsteins; they did not possess the SLICK phenotype but rather had plentiful hair on face, poll, and switch. These animals were categorized as relatives. Classification as slick or relative was confirmed in genotyping experiments for some animals (described below). The third group of cows, classified as wild-type, was composed of Holsteins produced by matings of normal-haired Holsteins. These cows possessed hair coats similar in appearance to cows of the relative group.

\section{Genotyping}

Genomic DNA was isolated from whole blood using the Gentra Puregene Blood Kit (Qiagen, Gaithersburg, MD). Concentration of DNA was measured using a Nanodrop 1000 (Thermo Fisher Scientific, Wilmington, $\mathrm{DE})$ and Quant-iT Picogreen assays from Invitrogen (La Jolla, CA). Stock DNA was diluted to $75 \mathrm{ng} / \mu \mathrm{L}$ and aliquoted for processing on a BovineHD BeadChip assay (Illumina Inc., San Diego, CA) according to the protocol supplied with the reagents. Processed chips were analyzed on an Illumina iScan, and SNP genotypes were called in Illumina's Genome Studio software. Animal samples with total SNP call rate $>90 \%$ were exported in PLINK format as AB allele calls. To determine haplotypes at the Senepol-derived SLICK locus, the approximate set of 22,000 SNP on Chr 20 were analyzed using fastphase (Scheet and Stephens, 2006) with a setting of a 50-SNP window. Haplotype identity by descent analysis was completed using an internal PERL script. The SLICK haplotype for animals in this study was confirmed based on association results from a separate genome-wide association analysis using a resource population of Senepol animals (Huson et al., 2014).

\section{Housing}

Studies were conducted at the University of Florida Dairy Unit, Hague, Florida $\left(29.77^{\circ} \mathrm{N}, 82.42^{\circ} \mathrm{W}\right)$. Cows were housed in sand-bedded freestall barns equipped with sprinklers (Rain Bird Manufacturing, Glendale, CA) and fans (J\&D Manufacturing, Eau Claire, WI) that were programmed to become activated when drybulb temperature exceeded $21.1^{\circ} \mathrm{C}$. When activated, the fans operated continuously and sprinklers were activated for 1.5 min at 6-min intervals. Feed and water were available ad libitum for all cows at all times. Cows were milked twice daily between 0800 and $1000 \mathrm{~h}$ and between 2100 and $2300 \mathrm{~h}$.

\section{Experiment 1: Diurnal Variation in Vaginal Temperature During Heat Stress}

Effect of the SLICK haplotype on diurnal variation in body temperature during heat stress was determined for slick cows $(\mathrm{n}=16)$, relatives $(\mathrm{n}=9)$, and wild-type cows $(\mathrm{n}=13)$. Slick cows were produced from 6 wildtype and 4 slick sires, whereas relatives were produced from 6 wild-type and 1 slick sire. Genotypes of 7 slick cows were tested, and all were heterozygous for the SLICK haplotype. Wild-type cows were selected from the herd to be similar in parity and stage of lactation as slick-haired and relative cows. We observed no significant differences $(P>0.05)$ among slick, relative, and wild-type cows in parity, DIM, or milk yield (least squares means $\pm \mathrm{SEM} ; 1.6 \pm 0.2,2.0 \pm 0.2$, and $1.7 \pm$ $0.2 ; 165 \pm 28,246 \pm 37$, and $189 \pm 31 \mathrm{~d} ;$ and $28.2 \pm$ $2.3,33.2 \pm 3.0$, and $33.7 \pm 2.5 \mathrm{~kg}$, for slick, relative, and wild-type, respectively) at the start of the experiment.

Vaginal temperature was measured at 15-min intervals for $3 \mathrm{~d}$ using a blank (i.e., without progesterone) controlled internal release device (CIDR; Zoetis, New York, NY) to which were attached 2 temperature data loggers: a Hobo water temperature Pro V2 (Onset Co., Bourne, MA; accuracy of $\pm 0.21^{\circ} \mathrm{C}$ from 0 to $50^{\circ} \mathrm{C}$ ) and iButton (model 1922T; Maxim Integrated, San Jose, $\mathrm{CA}$; accuracy of $\pm 0.0625^{\circ} \mathrm{C}$ at 11-bit resolution). The Hobo logger was taped to the CIDR using surgical adhesive tape, whereas the iButton was placed in a groove cut into central arm of the CIDR and affixed with silicone (Figure 2). Vaginal temperature was monitored as an indication of core body temperature because of the high correlation with rectal temperature $(\mathrm{r}=0.81$; Vickers et al., 2010) and because data loggers could be maintained in the vagina for several days. 

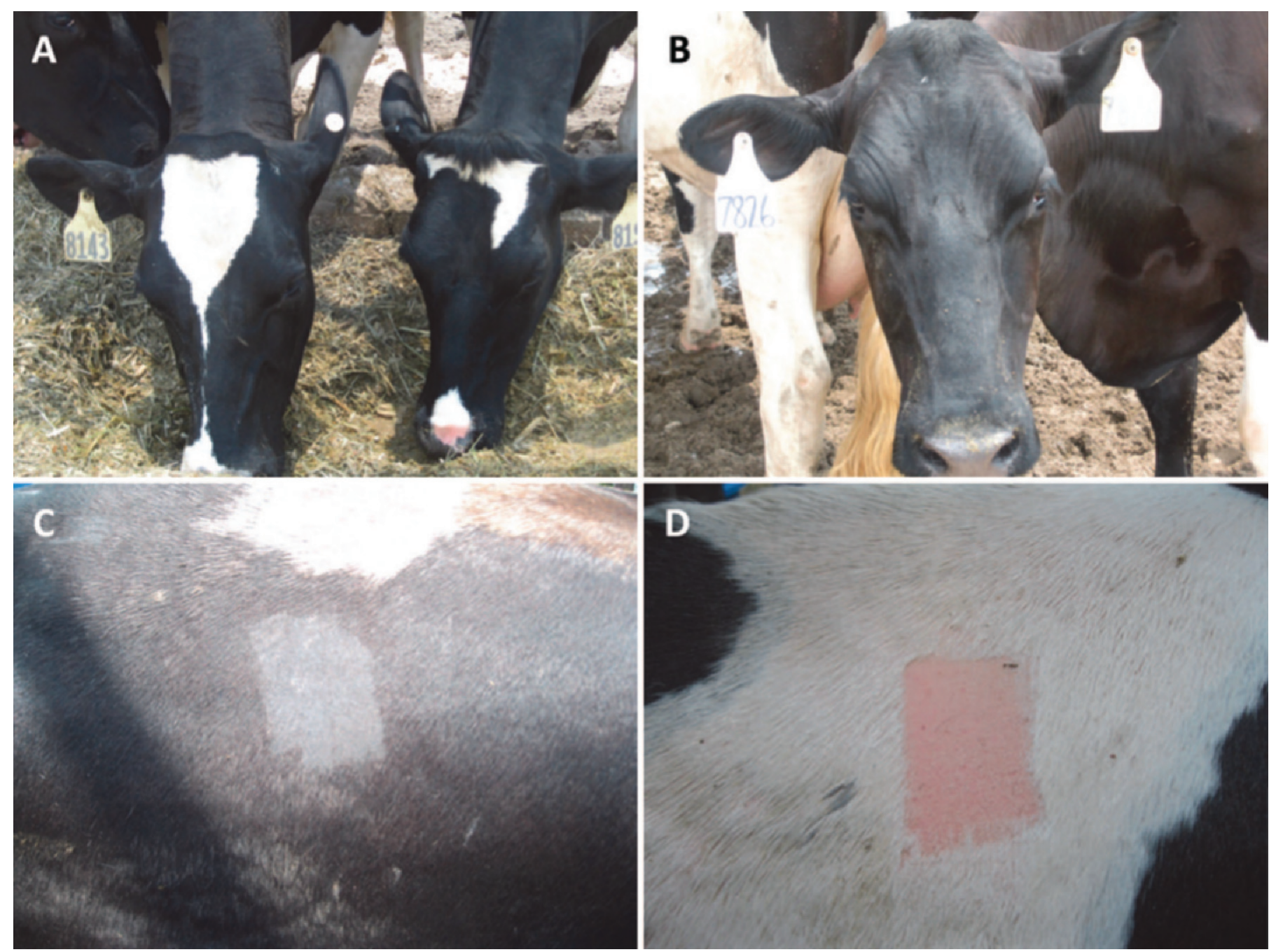

Figure 1. Representative examples of the slick phenotype in Holsteins. Panel A shows a slick (left) and non-slick cow; a close up of the face of a slick cow is shown in panel B. Note the absence of long hairs on the poll. Shown in panels C and D are examples of the shaved areas of the rump of slick (C) and wild-type (D) cows. Color version available in the online PDF.

The experiment was conducted between July 31 and August 3, 2012 (replicate 1), August 6 and August 9, 2012 (replicate 2), and August 10 and August 13, 2012 (replicate 3). A different set of cows was used for each replicate. On each experimental day, black globe temperature (inside and outside of the barn), dry bulb temperature, relative humidity $(\mathbf{R H})$, and dew point temperature were recorded every $15 \mathrm{~min}$ in the barn at a height of $2 \mathrm{~m}$. Dry bulb temperature, $\mathrm{RH}$, and dew point temperature were measured using a Hobo-U2 data logger (Onset Co.), and black globe temperature was measured using a Hobo Pro V2 data logger. The temperature-humidity index (THI) was calculated according to the equation of NRC (1971):

$$
\begin{gathered}
\text { THI }=(1.8 \times \mathrm{T}+32)- \\
{[(0.55-0.0055 \times \mathrm{RH}) \times(1.8 \times \mathrm{T}-26)],}
\end{gathered}
$$

where $\mathrm{T}=$ dry bulb temperature $\left({ }^{\circ} \mathrm{C}\right)$ and $\mathrm{RH}=$ relative humidity (\%).

\section{Experiment 2: Thermoregulatory Responses to Acute Heat Stress}

This experiment was conducted to determine whether the superior ability of slick-haired cows to regulate body temperature during heat stress was due to differences in surface temperature or sweating rate compared with cows without the slick-haired phenotype. Lactating slick $(\mathrm{n}=13)$, relative $(\mathrm{n}=9)$, and wild-type $(\mathrm{n}=9)$ cows were used. Slick cows were produced from 5 wild-type and 1 slick sires, whereas relatives were produced from 3 wild-type and 2 slick sires. Slick cows were genotyped: 10 were heterozygotes, 1 was a homozygote, and 2 were not genotyped. The experiment was conducted in five 


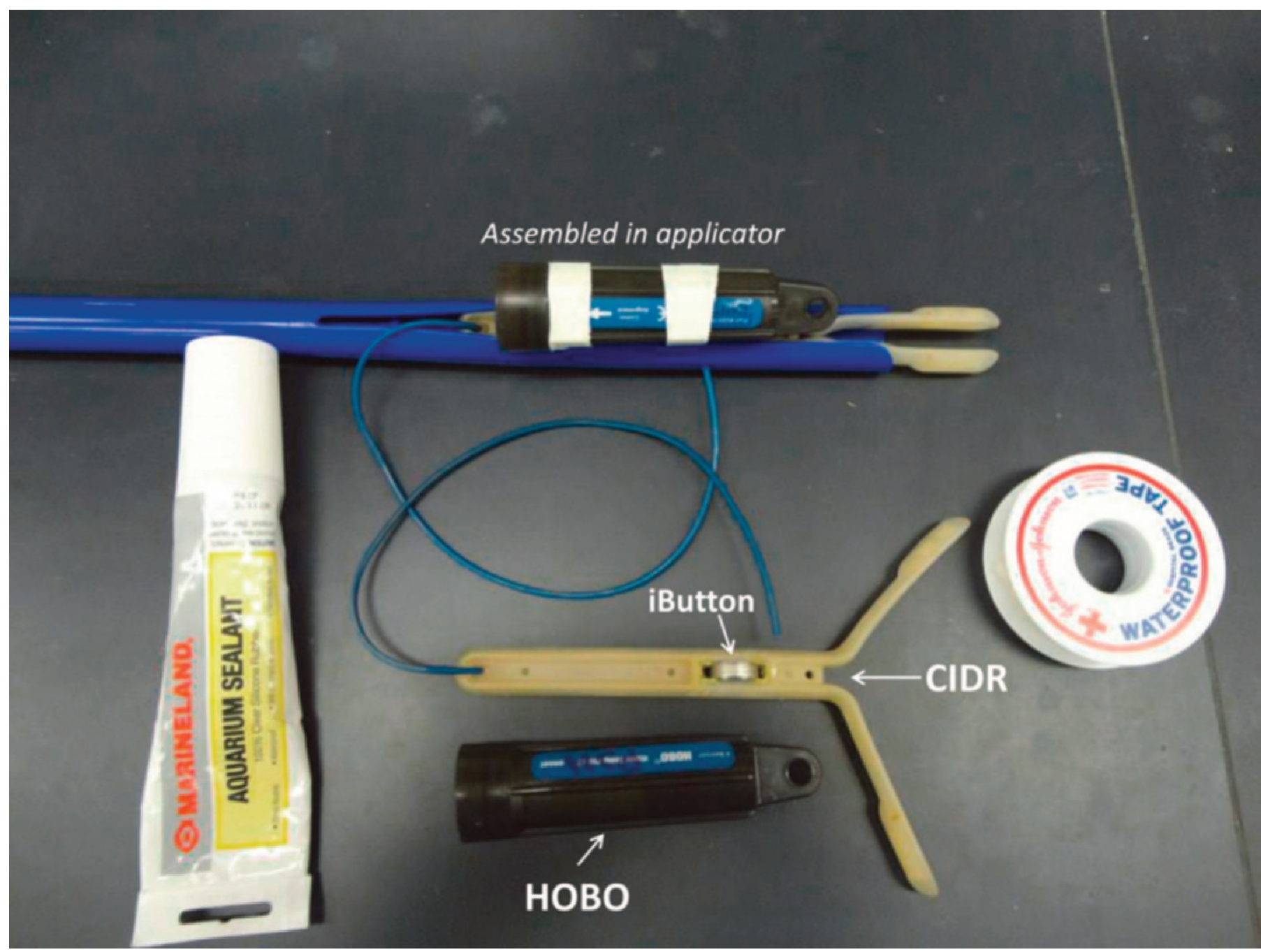

Figure 2. Devices used to measure vaginal temperature. Two temperature sensors were affixed to a blank controlled internal drug releasing (CIDR) device - an iButton (Maxim Integrated, San Jose, CA) and a Hobo water temperature Pro V2 (Onset Co., Bourne, MA). The iButton was placed into a groove cut into the CIDR and secured with aquarium sealant. The Hobo logger was taped to the CIDR using surgical adhesive tape. The CIDR was then loaded into an applicator for insertion into the vagina. Color version available in the online PDF.

1-d replicates during a period from July 30 to August 5, 2013, using a different group of cows in each replicate.

Slick, relative, and wild-type cows were matched according to milk yield, stage of lactation, coat color (percentage of the surface that was black), and parity. We found no significant effects of genetic type or genetic type $\times$ replicate on parity, DIM, or milk yield at the start of the trial. Parity was $2.0 \pm 0.2,2.1 \pm 0.2$, and $2.0 \pm 0.2$, DIM was $131.5 \pm 31.9,156.5 \pm 31.4$, and $132.7 \pm 32.6 \mathrm{~d}$, and milk yield was $33.4 \pm 2.2$, $38.0 \pm 2.1$, and $37.9 \pm 2.0 \mathrm{~kg} / \mathrm{d}$ for slick, relative, and wild-type cows, respectively.

For each replicate, cows were housed in an outdoor environment from 0800 to $1800 \mathrm{~h}$ in a $10-\times 8-\mathrm{m}$ pen. The pen had a concrete surface and was covered by shade cloth $(73 \%$ reduction in solar radiation; Dono- van Enterprises, Stuart, FL) suspended $3 \mathrm{~m}$ overhead. There were no sprinklers or fans for cooling. Feed and water were available ad libitum for all cows. Cows were milked before $(<0800 \mathrm{~h})$ and after the experiment $(2100$ h). Before the experiment, 4 areas of hair $(\sim 5 \times 5 \mathrm{~cm})$ were clipped on the right side of the cow using an Oster PowerPro hair clipper with Opti-Block blade kit (Oster Professional Products, McMinnville, TN). The clipped areas were located on the lower third of the neck, loin (at last thoracic vertebra), rump (at the middle of the tuber coxae and tuber ischii), and upper hind leg (at the femorotibial joint).

Rectal and surface temperatures and respiration and sweating rates were measured on each cow at 0900 , 1100, 1300, 1500, and 1700 h. Surface temperature and sweating rate were measured at the clipped regions 
and at an adjacent nonclipped area. Rectal temperature was measured by means of a digital thermometer (GLA M750; GLA Agricultural Electronics, San Luis Obispo, CA). Surface temperature was measured with an infrared thermometer (Sixth Sense LT300 Infrared Thermometer, TTI Instruments, Williston, VT) held at an angle of $90^{\circ}$ at a position $5 \mathrm{~cm}$ from the skin surface. Sweating rate was measured using the Vapometer device (Delfin Tech. Ltd., Kuopio, Finland), and respiration rate was determined by visual observations of flank movements for $1 \mathrm{~min}$.

On each experimental day, black globe temperature (inside and outside of the barn), dry bulb temperature, $\mathrm{RH}$, and dew point temperature were recorded every 1 min at a height of $2 \mathrm{~m}$. Dry bulb temperature, $\mathrm{RH}$, and dew point temperature were measured using a Hobo-U2 data logger (Onset Co.), and black globe temperature was measured using a Hobo Pro V2 data logger (Onset Co.).

\section{Experiment 3: Seasonal Variation in Milk Yield}

Daily milk yields for the first 90 DIM were obtained from a total of 11 slick and 274 wild-type cows calving between 2009 and 2011 at the University of Florida Dairy Unit (Hague). Data from 1, 2, or 3 lactations were available for each cow. Cows either calved in May, June, or July (warm season; $\mathrm{n}=9$ lactations from slick cows and 256 lactations from wild-type cows) or October, November, or December (cool season; $\mathrm{n}=9$ lactations from slick cows and 174 lactations from wild-type cows). Slick cows were produced from 5 wild-type sires and 3 slick sires. Only one slick cow was genotyped and she was a heterozygote. Calving months were chosen so that cows calving in the warm season would experience the first 90 DIM while exposed to hot weather, whereas cows calving in the cool season would experience the first 90 DIM while exposed to cool weather. Daily milk yield was measured at each milking by the AfiLab real time milk analyzer (S.A.E. Afikim, Kibbutz Afikim, Israel).

\section{Statistical Analysis}

Data from experiment 1 were analyzed by leastsquares ANOVA with the PROC GLIMMIX procedure of SAS (v. 9.3; SAS Institute Inc., Cary, NC). The statistical model included genetic type (slick, relative, and wild-type), replicate (1,2, and 3), time of day, stage of lactation (<100 DIM, 100-200 DIM, >200 DIM), parity (primiparous vs. multiparous), genetic type $\times$ time, genetic type $\times$ replicate, and cow (genetic type $\times$ replicate). Orthogonal contrasts were used to compare slick cows to relatives and wild-type cows and to com- pare relatives to wild-type cows. Cow was considered random and other main effects fixed. The relationship between vaginal temperatures recorded by the 2 devices was determined by linear regression analysis using the PROC GLM procedure of SAS.

Data from experiment 2 were analyzed by leastsquares ANOVA with the PROC GLIMMIX procedure of SAS (SAS Institute Inc.). The statistical model for sweating rate and surface temperature included genetic type (slick, relative and wild-type), replicate (1-5), region of body, clipping (shaved vs. unshaved), time of day, cow within genetic type by replicate, and all interactions. The statistical model for rectal temperature and respiration rate was similar except without the effect of region of body and clipping. Cow was considered random and other main effects fixed.

For experiment 3 , data were analyzed by least-squares ANOVA using the GLIMMIX procedure of SAS (SAS Institute Inc.). The model included main effects of genetic type (slick vs. wild-type), season of calving, year of birth, cow-year nested within genetic type by season $\times$ year, DIM, and all interactions. Tests of significance were calculated using expected mean squares; cow-year was considered random and other main effects were considered fixed.

\section{RESULTS}

\section{Experiment 1: Diurnal Variation in Vaginal Temperature}

Environmental conditions are shown in Figure 3. Dry bulb temperature and black globe temperature increased from a nadir at about $0700 \mathrm{~h}$ to a peak between 1100 and $1700 \mathrm{~h}$ before declining again. Relative humidity declined during the afternoon but THI followed the pattern of dry bulb and black globe temperatures.

Vaginal temperatures of cows were measured with 2 different data loggers. Data are only shown for measurements using the Hobo device because the correlation between measurements using the 2 different devices was 0.97 and statistical effects were similar. The linear regression equation for the relationship between vaginal temperatures using the 2 devices was as follows:

$$
\mathrm{VT}_{\mathrm{iBut}}=0.840+0.983 \mathrm{VT}_{\text {Hobo }}
$$

where $\mathrm{VT}_{\mathrm{iBut}}=$ vaginal temperature recorded by iButton, and $\mathrm{VT}_{\text {Hobo }}=$ vaginal temperature recorded by the Hobo device.

Effect of genetic type on diurnal variation in vaginal temperature is shown in Figure 4. Lowest temperatures occurred between 0800 and $0900 \mathrm{~h}$. Temperatures then increased until about 1300 to $1400 \mathrm{~h}$, increased again 


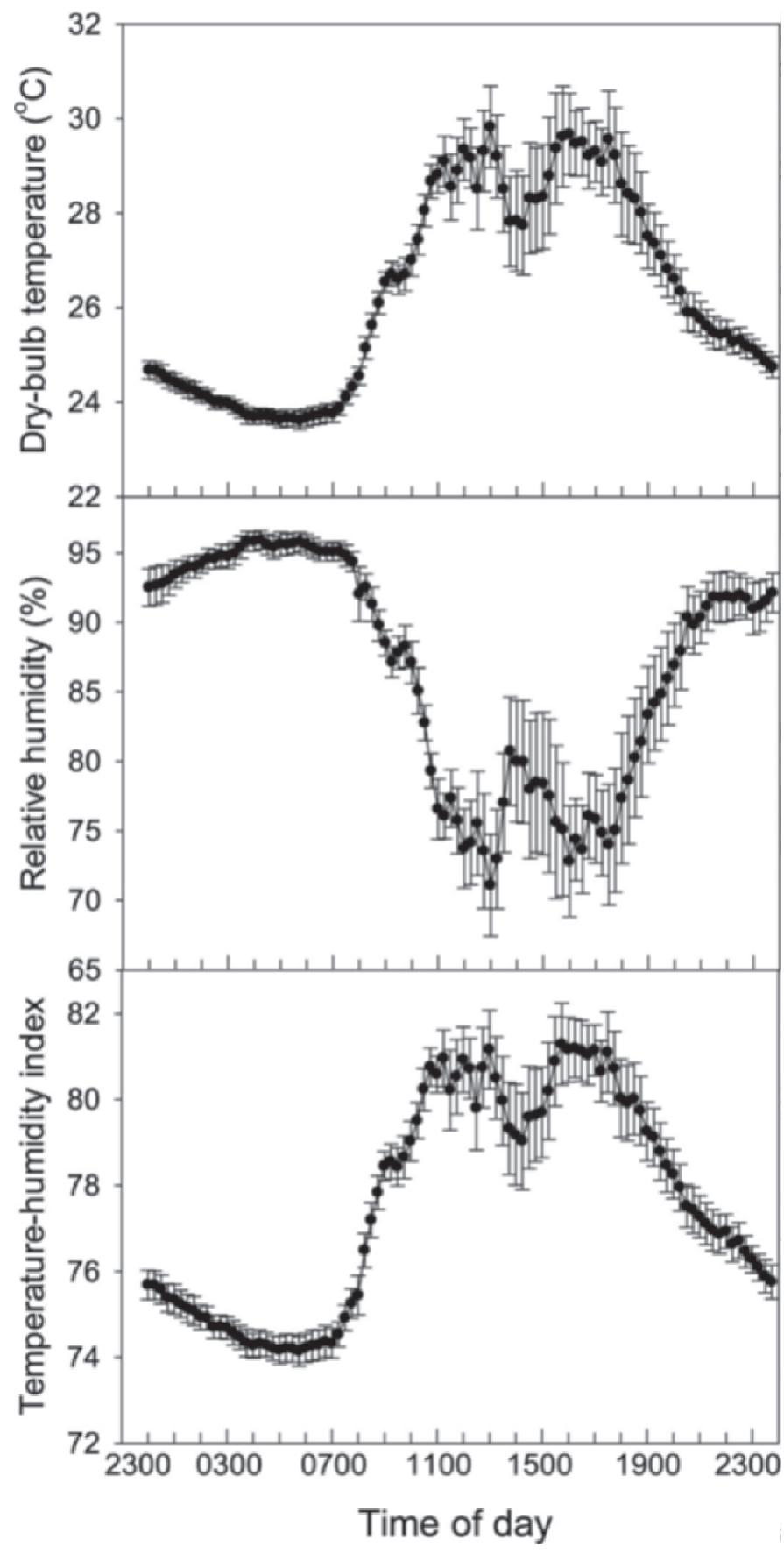

Figure 3. Thermal environment during the experiment to measure diurnal variation in vaginal temperature during heat stress in slick and wild-type Holstein cattle (experiment 1). Data represent least squares means \pm SEM.

between 0000 and $0500 \mathrm{~h}$ (except in slick cows), and then declined commencing at 0500 to $0600 \mathrm{~h}$. Vaginal temperature varied between genetic types $(P<0.0001)$, with slick cows having lower vaginal temperatures than relatives and wild-type cows. We observed no significant difference in vaginal temperature between relatives and

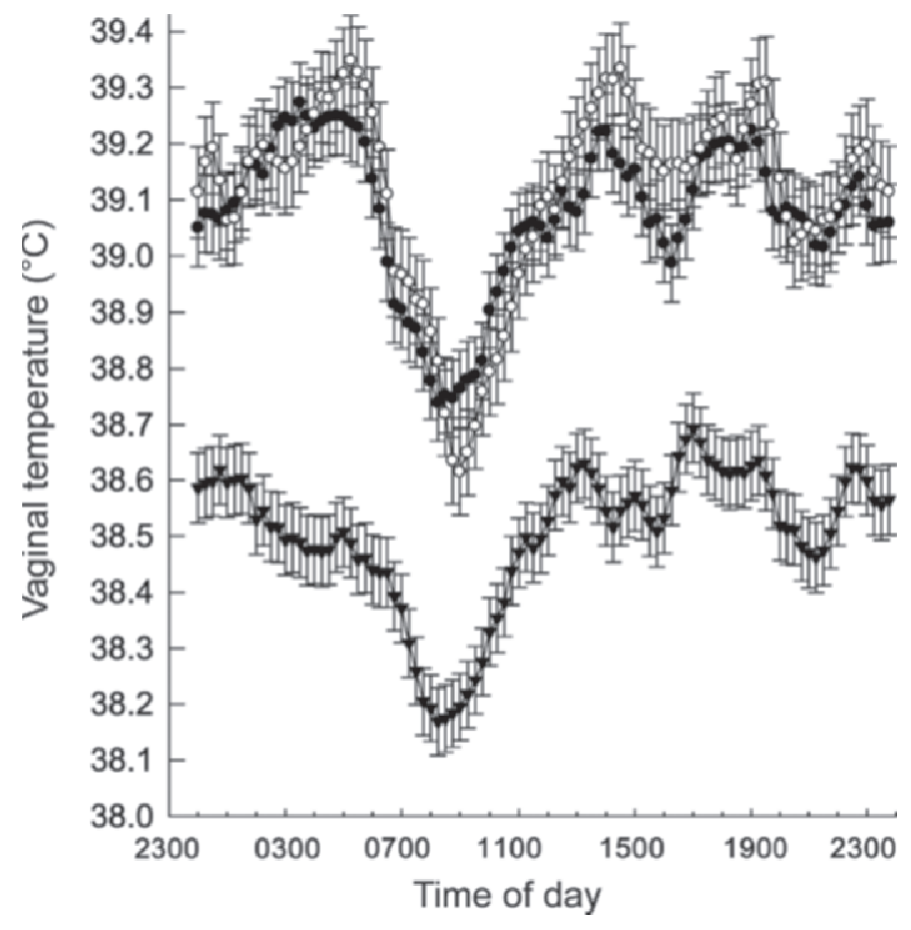

Figure 4. Diurnal variation in vaginal temperature during heat stress as affected by genetic type (experiment 1). Temperature was measured using a Hobo device (Onset Co., Bourne, MA). Data represent least squares means \pm SEM of results for wild-type (closed circles), relatives (open circles) and slick cows (closed triangles).

wild-type cows. The least squares means ( \pm SEM) for vaginal temperature were $38.5 \pm 0.04^{\circ} \mathrm{C}$ for slick cows, $39.1 \pm 0.05^{\circ} \mathrm{C}$ for wild-type cows, and $39.1 \pm 0.05^{\circ} \mathrm{C}$ for relatives. Genetic type $\times$ time interactions were not significant, indicating that differences between genetic types occurred throughout the day.

We detected effects of stage of lactation $(P<0.0001)$ and an interaction between stage and genetic type $(P<$ $0.0001)$ that reflect reduced effects of stage of lactation for slick cows. For wild-type Holsteins, vaginal temperature was greater for cows $<100$ DIM (least squares means $\pm \mathrm{SEM}=39.8 \pm 0.12^{\circ} \mathrm{C}$ ) than for cows between 100 and 200 DIM $\left(38.8 \pm 0.06^{\circ} \mathrm{C}\right)$ or $>200$ DIM $(38.7 \pm$ $0.04^{\circ} \mathrm{C}$ ). For relatives, rectal temperatures varied from $39.4 \pm 0.13^{\circ} \mathrm{C}$ for $<100 \mathrm{DIM}, 39.3 \pm 0.06^{\circ} \mathrm{C}$ for 100 to $200 \mathrm{DIM}$, and $38.7 \pm 0.05^{\circ} \mathrm{C}$ for $>200$ DIM, respectively). For slick cows, vaginal temperatures were 38.7 $\pm 0.05,38.4 \pm 0.07$, and $38.4 \pm 0.07^{\circ} \mathrm{C}$ for $<100,100$ to 200 , and $>200$ DIM, respectively.

\section{Experiment 2: Thermoregulation During Acute Heat Stress}

Environmental conditions during the experiment are summarized in Figure 5. The magnitude of heat stress 
increased over time, as indicated by changes in dry bulb and black globe temperatures and THI. Note that THI increased over time even though $\mathrm{RH}$ declined (Figure $5)$.

Rectal temperature also increased over time $(P<$ 0.0001 ), peaking at $1300 \mathrm{~h}$ (Figure 6A). The increase depended upon genetic type. We observed an effect of genetic type $(P<0.0001)$ and genetic type $\times$ time $(P$ $<0.0001)$. Orthogonal contrasts indicated that rectal temperature was lower $(P<0.0001)$ in slick Holsteins $\left(39.6 \pm 0.05^{\circ} \mathrm{C}\right)$ than in wild-type cows $\left(40.5 \pm 0.05^{\circ} \mathrm{C}\right)$ or relatives $\left(40.3 \pm 0.05^{\circ} \mathrm{C}\right)$. Moreover, rectal temperature was lower in relatives than in wild-type cows $(P<$ $0.02)$. The interaction reflected the fact that differences between genetic types were least at $0900 \mathrm{~h}$ compared with later times in the day.
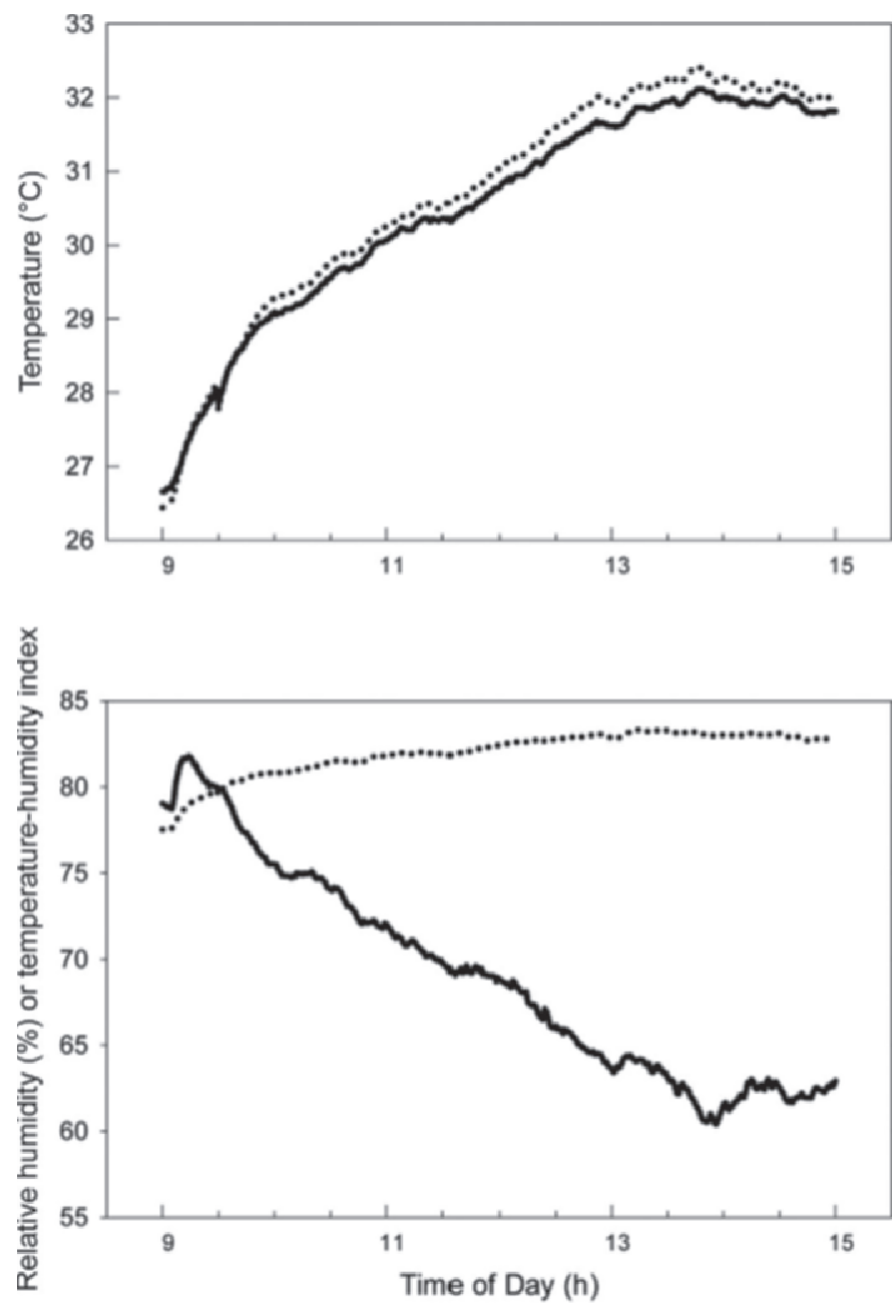

Figure 5. Thermal environment during the experiment to measure acute responses to heat stress (experiment 2). The top graph represents dry bulb temperature (solid line) and black globe temperature (dotted line), and the bottom graph represents relative humidity (solid line) and temperature-humidity index (dotted line).
As shown in Figure $6 \mathrm{~B}$, respiration rate was also affected by time $(P<0.0001)$, genetic type $(P<$ $0.0001)$, and their interaction $(P<0.0001)$. Respiration increased from 0900 to $1100 \mathrm{~h}$ and remained high thereafter. Orthogonal contrasts indicated that respiration rate was lower $(P<0.0001)$ in slick Holsteins $(93 \pm 0.7$ breaths per minute) than in wild-type cows $(107 \pm 0.8$ breaths per minute) or relatives (101 \pm 0.7 breaths per minute) and lower in relatives than in wild-type cows $(P<0.0001)$. The interaction was because differences between genetic types were lowest in the morning.

Skin temperature and sweating rate were measured at 4 body locations and on adjacent areas that were either shaved or not shaved. Skin temperature was affected by genetic type $(P<0.0005)$, time $(P<0.0001)$, and genetic type $\times$ time $(P<0.05)$. Skin temperature increased between 0900 and $1100 \mathrm{~h}$ and then decreased by $1500 \mathrm{~h}$ (Figure 6C). Using orthogonal contrasts, skin temperature was found to be lower for slick cows than for wild-type cows or relatives $(P<0.0001)$; wild-type cows and relatives did not differ (Figure 6C). Skin temperature was also affected by location $(P<0.0001)$ and region $\times$ time $(P<0.001)$ : temperature was higher at the 2 regions measured along the dorsal surface of the animal (loin and rump) than at the 2 regions measured lower on the animal (neck and hind leg). Skin temperatures were $36.4 \pm 0.12^{\circ} \mathrm{C}, 39.1 \pm 0.12^{\circ} \mathrm{C}, 39.4 \pm$ $0.12^{\circ} \mathrm{C}$, and $36.0 \pm 0.12^{\circ} \mathrm{C}$ for the neck, loin, rump, and hind leg, respectively. Overall, we detected no effect of shaved versus nonshaved on skin temperature but we did observe a location $\times$ shave interaction $(P<0.0001)$. The interaction occurred because skin temperature was higher for the shaved area than the nonshaved area for the hind $\operatorname{leg}\left(36.5 \pm 0.16^{\circ} \mathrm{C}\right.$ vs. $\left.35.4 \pm 0.16^{\circ} \mathrm{C}\right)$ but not for other areas.

Sweating rate was affected by genetic type $(P=0.08)$, time $(P<0.0001)$, and genetic type $\times$ time interaction $(P<0.0003$; Figure $6 \mathrm{D})$. Sweating rate increased from 0900 to $1300 \mathrm{~h}$ and then remained constant (wildtype) or decreased slightly (slick and relatives). Using orthogonal contrasts, sweating rate was found to be higher for slick cows than for wild-type cows or relatives $(P<0.003)$ and we found no difference between wild-type cows and relatives. Sweating rate was also affected by location $(P<0.001)$, region $\times$ time $(P$ $<0.04)$, shaved versus nonshaved $(P<0.0001)$, and the interaction between location $\times$ shaving $(P<0.04$; Figure 7). Sweating rate was greatest for the neck and loin, intermediate for the rump, and least for the hind leg (Figure 7). Sweating rate was greater for the shaved than the nonshaved area for all locations but the interaction occurred because shaving increased sweating rate to the greatest extent for the loin and rump and to the least extent for the neck and hind leg (Figure 7). 

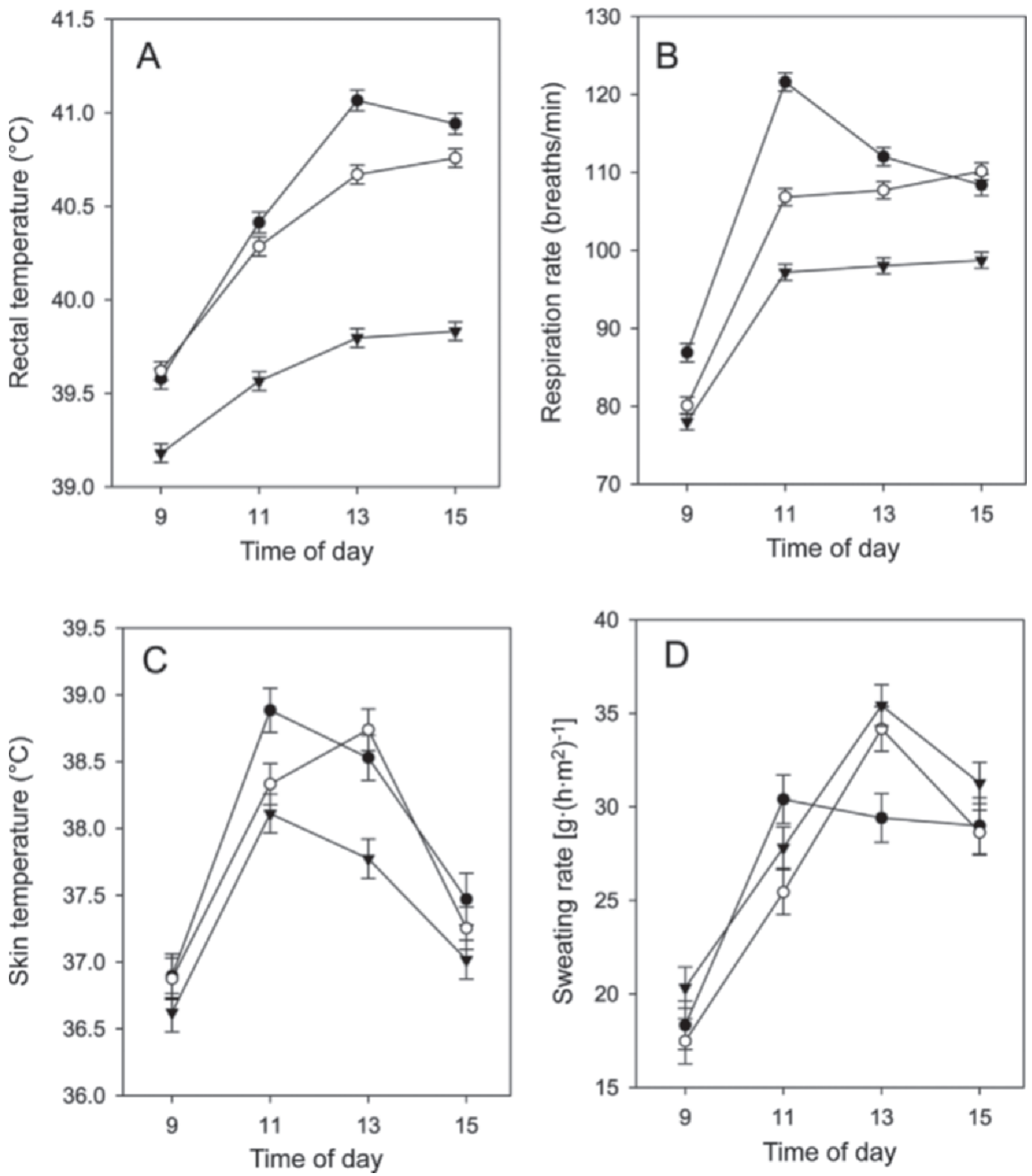

Figure 6. Acute response to heat stress in cows managed under shade cloth (experiment 2). Data represent least squares means \pm SEM of results for wild-type (closed circles), relatives (open circles), and slick cows (closed triangles).

There were, however, no interactions of genetic type with either location or shaved versus nonshaved with genetic type.

\section{Experiment 3: Seasonal Variation in Milk Production Traits During the First 90 DIM}

Milk yield was affected by a genetic type $\times$ season of calving $\times$ DIM interaction $(P<0.0001)$. The interaction resulted because calving in summer resulted in a smaller decrease in milk yield for slick cows than for wild-type cows, and these differences were more pro- nounced after the first week of lactation than in the first week (Figure 8). Across all DIM, the reduction in daily milk yield in summer compared with winter was $1.3 \mathrm{~kg}$ for slick cows and $3.7 \mathrm{~kg}$ for wild-type cows (Table 1).

We detected 3-way interactions for percentage fat, protein, and lactose $(P<0.0001)$. The interaction for percentage fat represented the fact that the summer depression in milk fat was apparent later in lactation for slick cows than for wild-type cows but was of a greater magnitude for slick cows during this time (Figure 9). Across all DIM, the reduction in fat percentage in sum- 


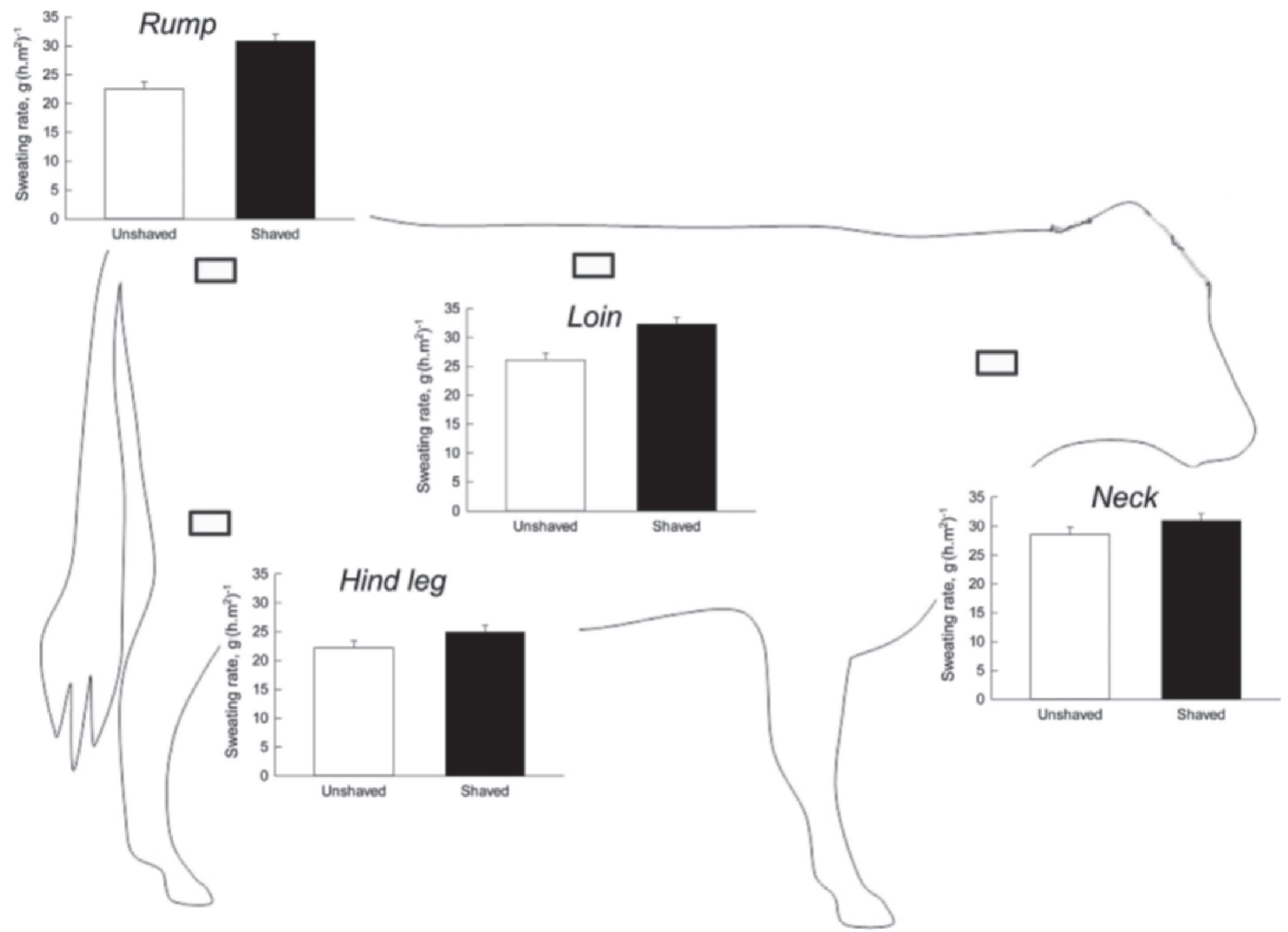

Figure 7. Interactions between body location and shaving on sweating rate for cows placed under shade cloth during heat stress (experiment 2). The approximate location of each region in which sweating was examined is indicated by the small box. Data represent least squares means \pm SEM of results for shaved and unshaved areas in each body region.

mer compared with winter was $0.19 \%$ for slick cows and $0.13 \%$ for wild-type cows (Table 1 ). The reduction in percentage protein and percentage lactose during the summer was also greater for slick cows than for wild-type cows, with differences between genetic types occurring after $\sim 5$ to 10 DIM (Figures 10 and 11). For percentage lactose, the interaction also reflected that differences between summer and winter were reduced after about 35 to 40 DIM in slick cows and about 50 DIM in wild-type cows. Across all DIM, the reduction in protein percentage in summer compared with winter was $0.22 \%$ for slick cows and $0.12 \%$ for wild-type cows (Table 1). The reduction in lactose percentage in summer compared with winter was $0.17 \%$ for slick cows and $0.12 \%$ for wild-type cows (Table 1 ).

Somatic cell score was also affected by a 3 -way interaction $(P<0.0001)$ : SCS was lower in summer than in winter for slick cows on some days but not others, whereas season had no effect in wild-type cows (Figure 12). The reduction in SCS in summer compared with winter was $0.13 \%$ for slick cows and $0.05 \%$ for wild-type cows (Table 1).

\section{DISCUSSION}

Results from the present study confirm earlier findings that the slick-hair phenotype confers superior thermoregulation in dairy cows exposed to heat stress (Olson et al., 2003; Dikmen et al., 2008) and extends the range of environments in which this advantage is expressed to the freestall housing system. In addition to improving capacity for body temperature regulation, cows with slick hair were also resistant to heat stress with respect to milk yield. Whereas wild-type cows 
Table 1. Interactions between genetic type (i.e., slick vs. wild-type) and season of calving (i.e., winter or summer) on milk yield and composition during the first 90 DIM (experiment 3)

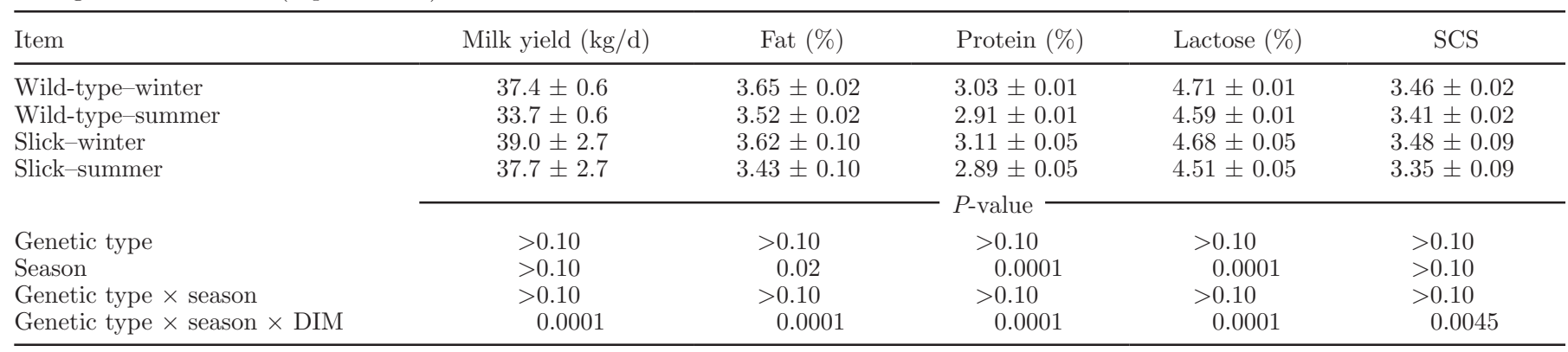

calving in the summer had lower milk yields than those calving in the winter, this difference was greatly reduced in slick-haired cows. Thus, it is likely that increasing the frequency of the SLICK haplotype in Holstein cows can reduce the negative consequences of heat stress on milk yield, even in situations where housing has been modified to reduce the effect of heat stress.

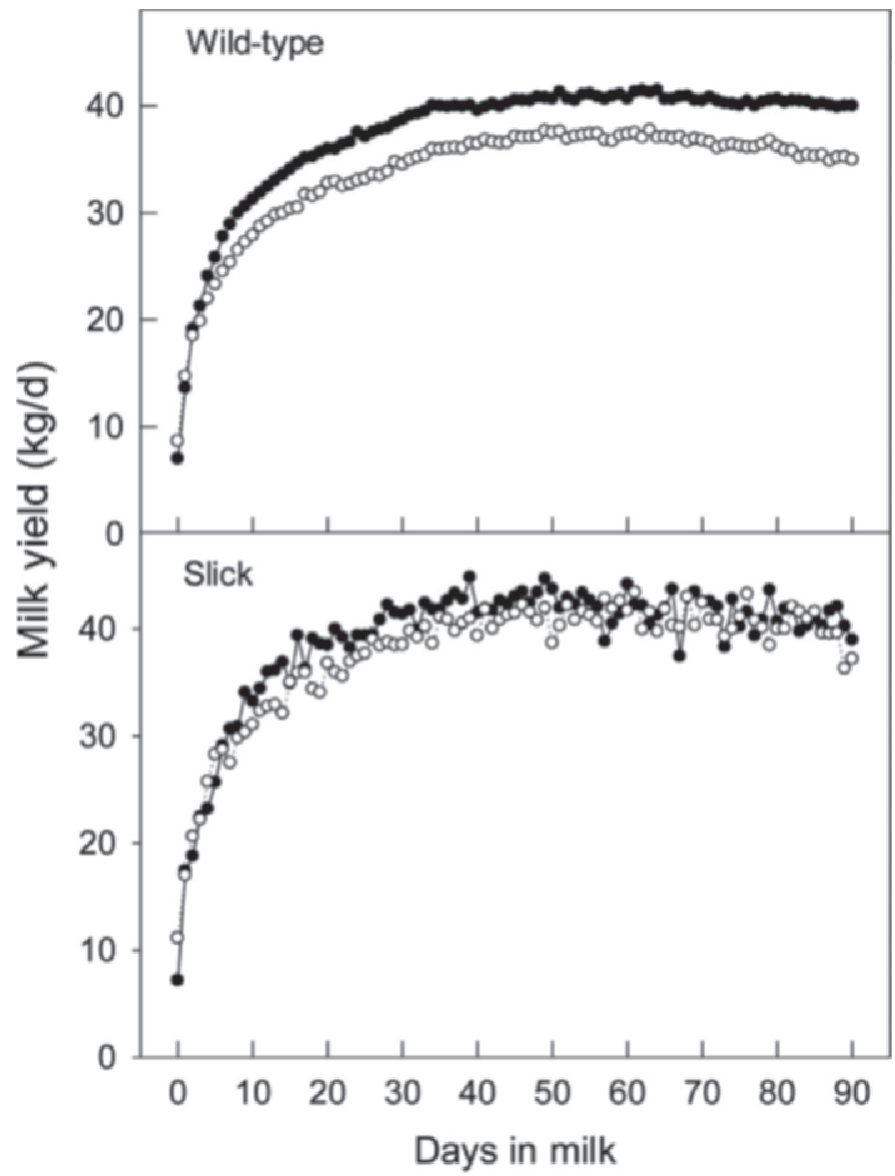

Figure 8. Milk yield during the first 90 DIM as affected by genetic type and season of calving (experiment 3). Winter is represented by solid circles and summer by open circles. Data represent least squares means. The pooled SEM was $0.31 \mathrm{~kg} / \mathrm{d}$ for wild-type cows and 1.50 $\mathrm{kg} / \mathrm{d}$ for slick cows.
The physiological basis for thermotolerance in slick cows involves multiple modes of heat loss to the environment. The short hair length caused by the SLICK haplotype reduces the insulation to conductive and convective heat loss in the hair coat (Berman, 2004) and thereby increases sensible heat loss. Evaporative heat loss is also heightened in slick cows because of the

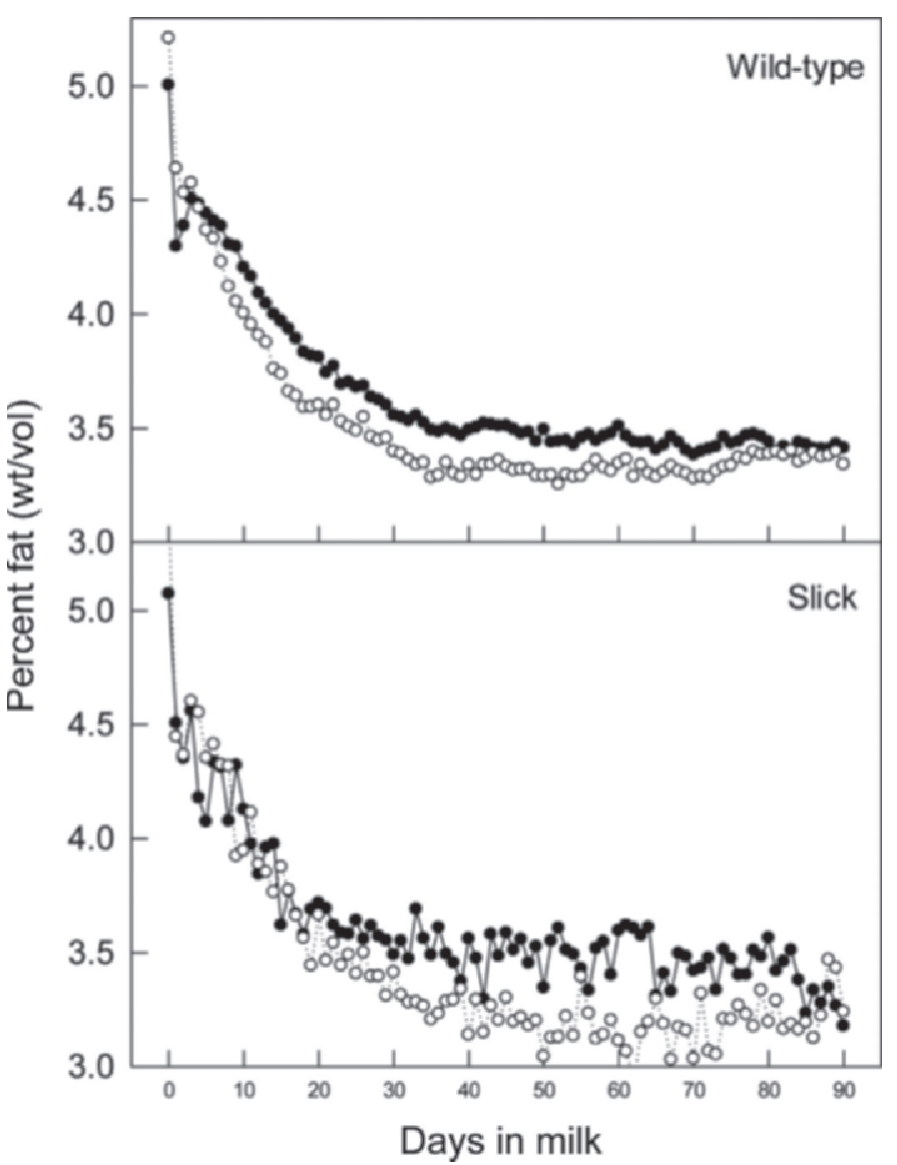

Figure 9. Percentage fat in milk during the first 90 DIM as affected by genetic type and season of calving (experiment 3). Winter is represented by solid circles and summer by open circles. Data represent least squares means. The pooled SEM was $0.027 \%$ for wild-type cows and $0.130 \%$ for slick cows. 


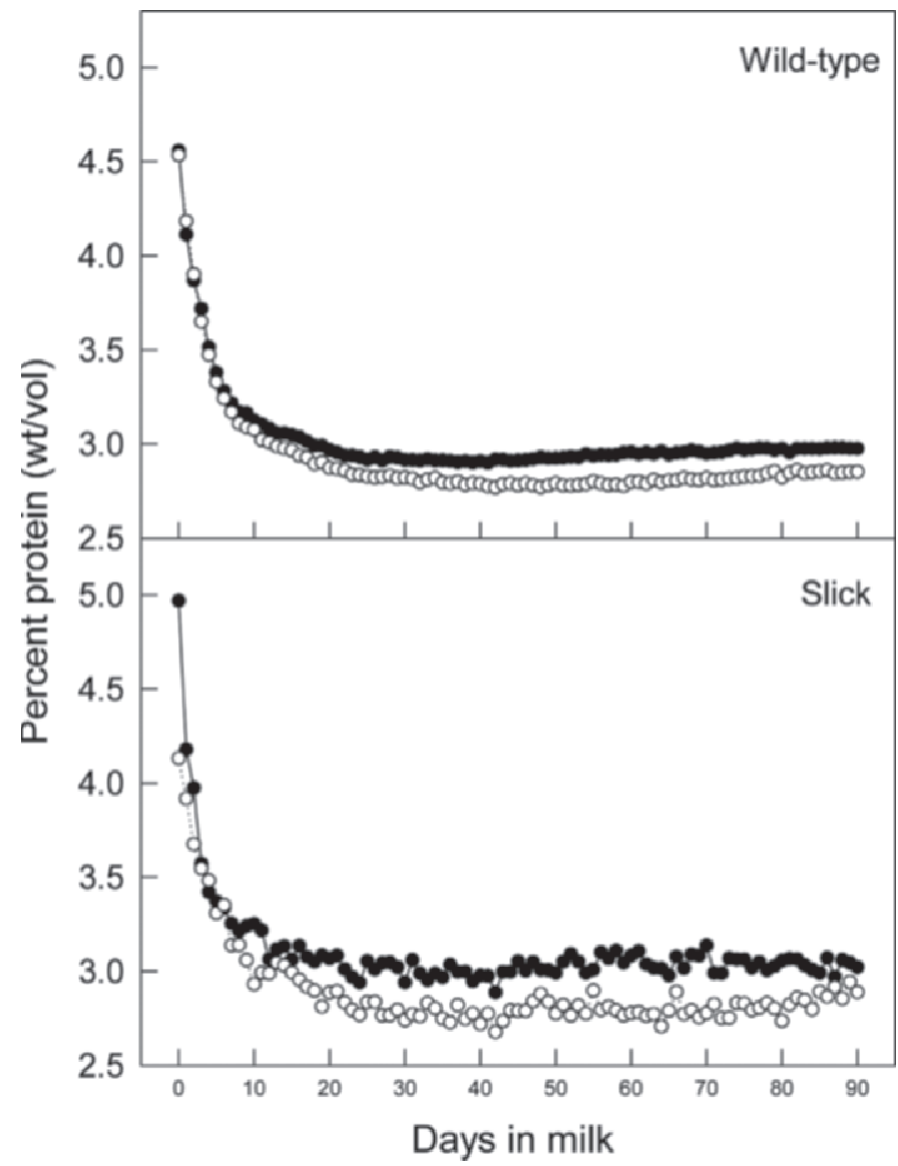

Figure 10. Percentage protein in milk during the first 90 DIM as affected by genetic type and season (experiment 3). Winter is represented by solid circles and summer by open circles. Data represent least squares means. The pooled SEM was $0.013 \%$ for wild-type cows and $0.062 \%$ for slick cows.

increased sweating rate during heat stress. In an earlier study, slick cows were found to lose more water by sweating than wild-type cows (Dikmen et al., 2008). In that study, in which sweating was measured at the shoulder, differences between slick and wild-type cows could be eliminated by shaving the hair and it was concluded that the elevated sweating rate in slick cows reflected reductions in trapping of humid air in the hair coat. In experiment 2 of the current study, however, where sweating was measured at the neck, loin, rump, and hind leg, differences in sweating rate between slick and wild-type cows were apparent for both shaved and unshaved areas of the skin. The interpretation is that either slick cows have a greater density of sweat glands than wild-type cows or individual glands of slick cows have increased capacity for sweat production. Evaporative heat loss is the major mode available to the cow for dissipation of metabolic heat (Maia et al., 2005) so the increased capacity of slick cows for sweating could be an important modification responsible for increased thermotolerance.

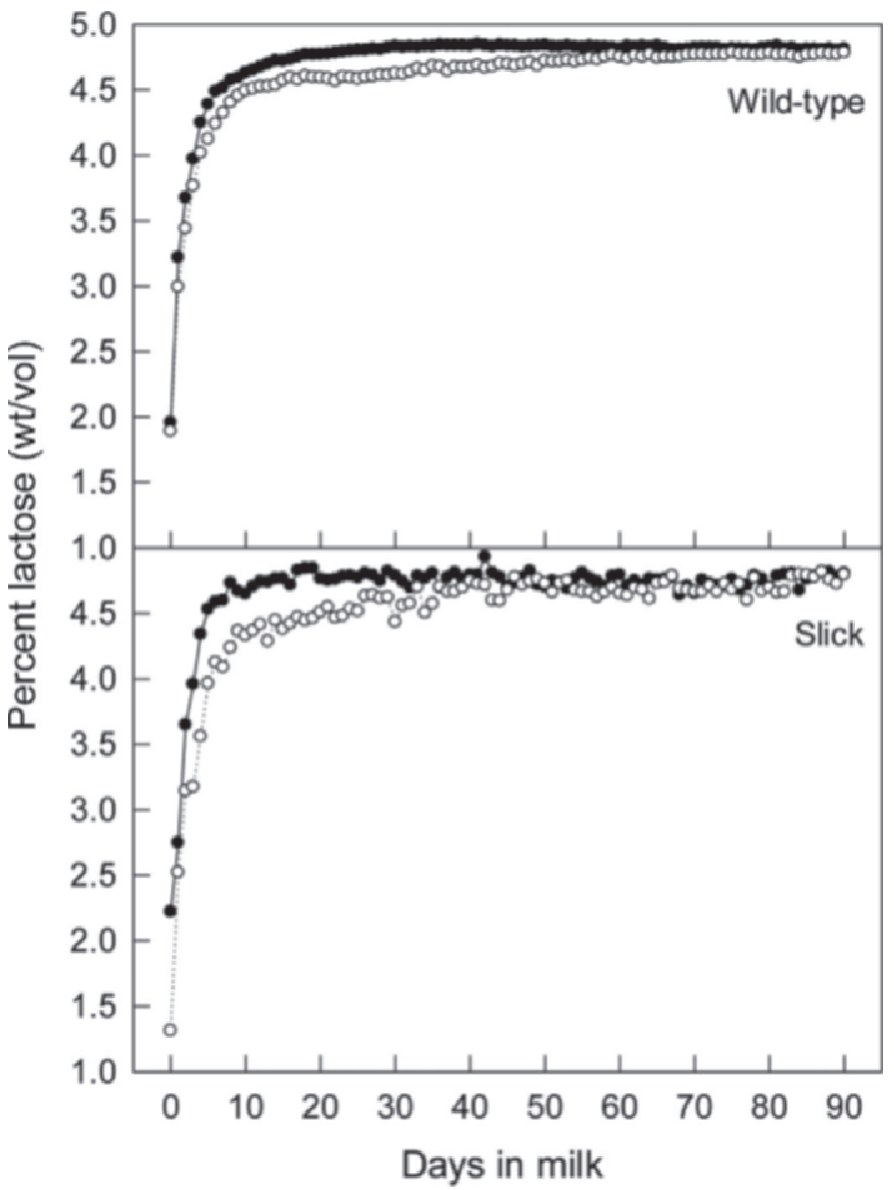

Figure 11. Percentage lactose in milk during the first 90 DIM as affected by genetic type and season of calving (experiment 3). Winter is represented by solid circles and summer by open circles. Data represent least squares means. The pooled SEM was $0.020 \%$ for wild-type cows and $0.098 \%$ for slick cows.

The fact that respiration rate increased to a lesser extent for slick cows than for wild-type cows is probably largely a reflection of the increased sweating rate of slick cows. Cows lose evaporative heat by both sweating and panting. Cutaneous water loss is greater than via the respiratory tract, with the difference widening with increasing environmental temperature (Kibler and Brody, 1952). The increased heat loss due to sweating in slick cows would have obviated the need for an increased respiration rate. One expected consequence would be increased utilization of water and minerals by slick cows to meet the demands of sweating, as well as reduced likelihood of respiratory alkalosis caused by alveolar ventilation in the lungs (Sanchez et al., 1994).

Another discrepancy between this study and that of Dikmen et al. (2008) is that skin temperature was lower in slick cows than in wild-type cows in experiment 2 of the present study, whereas no such difference between slick and wild-type cows was found in the earlier study. 


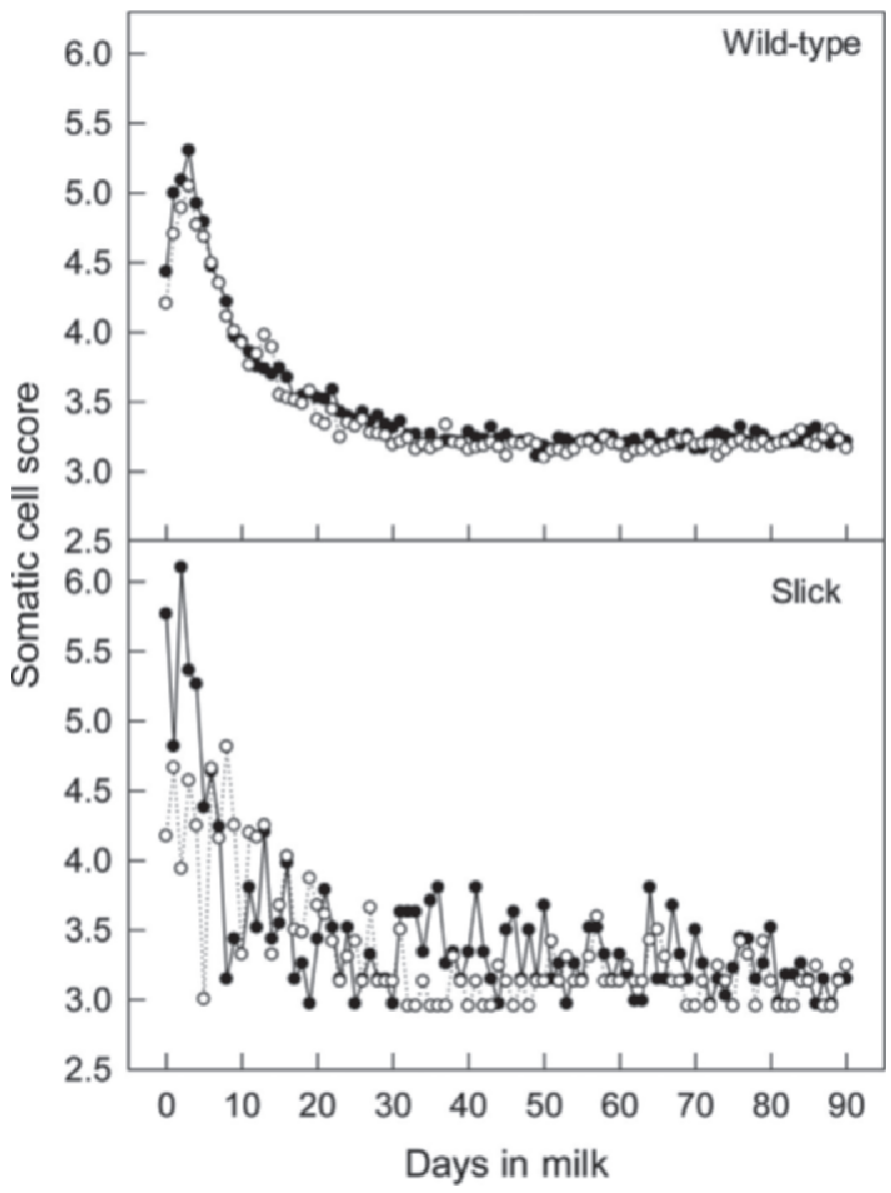

Figure 12. Somatic cell score in milk during the first 90 DIM as affected by genetic type and season of calving (experiment 3 ). Winter is represented by solid circles and summer by open circles. Data represent least squares means. The pooled SEM was 0.057 for wild-type cows and 0.278 for slick cows.

Present results are what would be expected given the increased rates of heat loss at the skin for slick cows.

The observation that there was little seasonal variation in milk yield in slick cows is consistent with the lower body temperatures experienced by slick cows in experiments 1 and 2 . The difference in vaginal temperature between slick and wild-type cows in experiment 1 was $0.6^{\circ} \mathrm{C}$, a value greater than the difference in rectal temperature between cooled and control cows in some studies in which cooling during the summer improved milk yield (Igono et al., 1985; Chen et al., 1993). Differences in milk composition between cows calving in winter versus summer were also modified in slick cows, with seasonal differences in percentage fat, protein, and lactose as well as SCS being exacerbated in slick cows. Analysis of seasonal data in Florida indicates that heat stress is associated with decreases in percentage fat and protein (Rodriquez et al., 1985). However, seasonal variation in milk composition can be difficult to interpret with respect to heat stress because of possible variation in diet and other management factors. Few experimental studies have determined effects of heat stress on milk composition. Heat stress decreased percentage fat and protein but not lactose in one experiment involving only 4 cows (Bandaranayaka and Holmes, 1976). Cooling cows in summer in Argentina did not affect percentage protein or lactose (Gallardo et al., 2005). In that same study, cooling increased fat percentage for cows fed a diet with a 80:20 forage:concentrate ratio but reduced fat percentage for cows fed a diet with a 70:30 forage:concentrate ratio. More work is required to understand how the slick phenotype affects changes in milk composition. The observation that seasonal effects on milk fat, protein, and lactose were altered in slick cows suggests the possibility that the SLICK haplotype is associated in a complex way with milk composition. Moreover, some of the economic advantage associated with the SLICK haplotype in the summer associated with reduced effect of heat stress on milk yield would be offset if seasonal effects on composition are exaggerated in cows of this genotype.

Interestingly, cows that were relatives of slick cows without inheriting the SLICK haplotype showed improved capacity for regulation of body temperature compared with wild-type Holsteins in experiment 2. These cows were intermediate between wild-type and slick cows with respect to diurnal variation in rectal temperature. Regulation of body temperature is heritable in Holsteins (Dikmen et al., 2012, 2013). The improved thermoregulation of relatives could represent random variation in genetic merit for body temperature regulation among the parents of the relative cows or heterosis from the small percentage of Senepol remaining in these animals (some evidence exists for heterosis in body temperature regulation; Dikmen et al., 2009); alternatively, the SLICK haplotype is not the only gene conferring thermotolerance that was introduced from the founder Senepol animals. Indeed, the small numbers of animals categorized as slick and relatives means that genetic characteristics of founder animals could have affected physiological and production responses to heat stress.

In conclusion, Holstein cows inheriting the SLICK haplotype from Senepol cattle have superior ability to regulate body temperature, at least in part because of increased capacity for sweating, and they experience less-pronounced reductions in milk yield during the summer in a hot environment.

\section{ACKNOWLEDGMENTS}

This research was supported by Agriculture and Food Research Initiative Competitive Grants no. 2010- 
85122-20623 and 2013-68004-20365 from the USDA National Institute of Food and Agriculture (Washington, DC) and a grant from Southeast Milk Inc. Milk Check-off Program. The authors acknowledge the efforts of Timothy A. Olson in establishing the SLICK gene in Holsteins, data collection by Anna C. Denicol, Sofia Ortega, and Paula Tribulo (all from Department of Animal Sciences, University of Florida, Gainesville), and the assistance of Eric Diepersloot and staff of the University of Florida Dairy Unit.

\section{REFERENCES}

Bandaranayaka, D. D., and C. W. Holmes. 1976. Changes in the composition of milk and rumen contents in cows exposed to a high ambient temperature with controlled feeding. Trop. Anim. Health Prod. 8:38-46.

Berman, A. 2004. Tissue and external insulation estimates and their effects on prediction of energy requirements and of heat stress. J. Dairy Sci. 87:1400-1412.

Chen, K. H., J. T. Huber, C. B. Theurer, D. V. Armstrong, R. C. Wanderley, J. M. Simas, S. C. Chan, and J. L. Sullivan. 1993. Effect of protein quality and evaporative cooling on lactational performance of Holstein cows in hot weather. J. Dairy Sci. 76:819-825.

Dikmen, S., E. Alava, E. Pontes, J. M. Fear, B. Y. Dikmen, T. A. Olson, and P. J. Hansen. 2008. Differences in thermoregulatory ability between slick-haired and wild-type lactating Holstein cows in response to acute heat stress. J. Dairy Sci. 91:3395-3402.

Dikmen, S., J. B. Cole, D. J. Null, and P. J. Hansen. 2012. Heritability of rectal temperature and genetic correlations with production and reproduction traits in dairy cattle. J. Dairy Sci. 95:3401-3405.

Dikmen, S., J. B. Cole, D. J. Null, and P. J. Hansen. 2013. Genome wide association mapping for identification of quantitative trait loci for rectal temperature during heat stress in Holstein cattle. PLoS ONE 8:e69202.

Dikmen, S., L. Martins, E. Pontes, and P. J. Hansen. 2009. Genotype effects on body temperature in dairy cows under grazing conditions in a hot climate including evidence for heterosis. Int. J. Biometeorol. 53:327-331.

Flori, L., M.I. Gonzatti, S. Thevenon, I. Chantal, J. Pinto, D. Berthier, P. M. Aso, and M. A. Gautier. 2012. A quasi-exclusive European ancestry in the Senepol tropical cattle breed highlights the importance of the slick locus in tropical adaptation. PLoS ONE 7:e36133.

Gallardo, M. R., S. E. Valtorta, P. E. Leva, M. C. Gaggiotti, G. A. Conti, and R. F. Gregoret. 2005. Diet and cooling interactions on physiological responses of grazing dairy cows, milk production and composition. Int. J. Biometeorol. 50:90-95.

Hayes, B. J., P. J. Bowman, A. J. Chamberlain, K. Savin, C. P. van Tassell, T. S. Sonstegard, and M. E. Goddard. 2009. A validated genome wide association study to breed cattle adapted to an environment altered by climate change. PLoS ONE 4:e6676.

Huson, H. J., E. S. Kim, R. W. Godfrey, T. A. Olson, M. C. McClure, C. C. Chase, R. Rizzi, A. M. O'Brien, C. P. Van Tassell, J. F. Garcia, and T. S. Sonstegard. 2014. Genome-wide association study and ancestral origins of the slick-hair coat in tropically adapted cattle. Front. Genet. 5:101.

Igono, M. O., B. J. Steevens, M. D. Shanklin, and H. D. Johnson. 1985. Spray cooling effects on milk production, milk, and rectal temperatures of cows during a moderate temperate summer season. J. Dairy Sci. 68:979-985.

Kibler, H. H., and S. Brody. 1952. Environmental physiology, with special reference to domestic animals. XIX. Relative efficiency of surface evaporative, respiratory evaporative, and non-evaporative cooling in relation to heat production in Jersey, Holstein, Brown Swiss and Brahman cattle, $5^{\circ}$ to $105^{\circ}$ F. Mo. Agric. Exp. Sta. Res. Bull. 497. Univ. Missouri Agric. Exp. Sta., Columbia.

Maia, A. S. C., R. G. daSilva, and C. M. Battiston Loureiro. 2005. Sensible and latent heat loss from the body surface of Holstein cows in a tropical environment. Int. J. Biometeorol. 50:17-22.

Mariasegaram, M., C. C. Chase Jr., J. X. Chaparro, T. A. Olson, R. A. Brenneman, and R. P. Niedz. 2007. The slick hair coat locus maps to chromosome 20 in Senepol-derived cattle. Anim. Genet. 38:54-59.

NRC. 1971. A Guide to Environmental Research on Animals. Natl Acad. Sci., Washington, DC.

Olson, T. A., C. Lucena, C. C. Chase Jr., and A. C. Hammond. 2003 Evidence of a major gene influencing hair length and heat tolerance in Bos taurus cattle. J. Anim. Sci. 81:80-90.

Rodriquez, L. A., G. Mekonnen, C. J. Wilcox, F. G. Martin, and W. A. Krienke. 1985. Effects of relative humidity, maximum and minimum temperature, pregnancy, and stage of lactation on milk composition and yield. J. Dairy Sci. 68:973-978.

Sanchez, W. K., D. K. Beede, and J. A. Cornell. 1994. Interactions of sodium, potassium, and chloride on lactation, acid-base status, and mineral concentrations. J. Dairy Sci. 77:1661-1675.

Scheet, P., and M. Stephens. 2006. A fast and flexible statistical model for large-scale population genotype data: Applications to inferring missing genotypes and haplotypic phase. Am. J. Hum. Genet. 78:629-644.

Vickers, L. A., O. Burfeind, M. A. G. von Keyserlingk, D. M. Veira, D. M. Weary, and W. Heuwieser. 2010. Technical note: Comparison of rectal and vaginal temperatures in lactating dairy cows. J. Dairy Sci. 93:5246-5251. 